Check for updates

Cite this: RSC Adv., 2018, 8, 27260

Received 2nd July 2018

Accepted 25th July 2018

DOI: $10.1039 / c 8 r a 05660 a$

rsc.li/rsc-advances

\section{Biomaterials from human bone - probing organic fraction removal by chemical and enzymatic methods}

\author{
A. P. Mamede, (D) a A. R. Vassalo, (iD) abc E. Cunha, (D) ${ }^{b}$ D. Gonçalves, (D) bcd \\ S. F. Parker, (D) ${ }^{\text {e }}$ L. A. E. Batista de Carvalho (iD *a and M. P. M. Marques (iD af
}

Two different deproteination and defatting processes of human bone were investigated, by combined infrared and neutron techniques: a previously reported hydrazine extraction and a newly developed multi-enzymatic treatment. Complementary Fourier transform infrared total attenuated reflectance and inelastic neutron scattering spectroscopies were applied, allowing access to all vibrational modes of the samples. The effectiveness of the different experimental protocols for removing the organic constituents of bone (lipids and protein) was probed, as well as their effect on bone's structural and crystallinity features. The results thus gathered are expected to have an impact on bioanthropological, archaeological and medical sciences, namely regarding the development of novel biocompatible materials for orthopaedic xenografts.

\section{Introduction}

Bone is a heterogeneous material containing inorganic and organic constituents: of the total weight of bone, $60-65 \%$ is ascribed to the inorganic matrix of hydroxyapatite $\left(\mathrm{Ca}_{10}\left(\mathrm{PO}_{4}\right)_{6}\right.$ $\mathrm{OH}_{x}$, HAp) (partly substituted by carbonate at both phosphate and hydroxyl sites), $25 \%$ to the organic components and $c a$. $10 \%$ to water. The organic phase comprises lipids and proteins (mainly type I collagen), the remaining $2 \%$ corresponding to various cellular constituents. ${ }^{\mathbf{1 , 2}}$ Upon diagenesis (post-mortem processes triggering physical and chemical alterations), bone undergoes changes in molecular structure often associated with warping and dimensional variations. ${ }^{3}$

The examination of human remains is routinely carried out by bioanthropologists and chemists to retrieve varied information, such as radiocarbon dating or post-mortem changes. ${ }^{\mathbf{4}-16}$ The skeleton often constitutes the only preserved remains found in archaeological and forensic settings and their importance for the study of past populations or for victim identification is unquestionable. However, retrieving information on the physical and chemical properties of the bone matrix (e.g. by

aUnidade de I\&D “Quimica-Física Molecular”, Department of Chemistry, University of Coimbra, Portugal.E-mail: labc@ci.uc.pt

${ }^{b}$ Lab. Forensic Anthropology, Centre for Functional Ecology, University of Coimbra, Portugal

${ }^{c}$ Research Centre for Anthropology and Health (CIAS), University of Coimbra, Portugal ${ }^{d}$ Archaeosciences Lab., Directorate General Cultural Heritage (LARC/CIBIO/InBIO), Lisbon, Portugal

${ }^{e}$ ISIS Facility, STFC Rutherford Appleton Laboratory, Chilton, Didcot, OX 11 OQX, UK ${ }^{f}$ Department of Life Sciences, University of Coimbra, Portugal spectroscopic or diffraction methods) is frequently hampered by the presence of organic components (lipids and proteins), the most abundant of which is type I collagen. Hence, the ability to successfully achieve defatting and deproteination of human skeletal remains, yielding an organic-free mineral framework, while preserving its native structural and physical properties, will have an immediate impact in several areas, from bioarchaeology (e.g. dating of ancient specimens), to forensics, biochemistry (e.g. enzyme immobilisation substrates), pharmacology (e.g. drug delivery matrices) and medicine. In particular, the development of biomaterials from animal bone for use as orthopaedic xenografts (bone grafts from a different animal species), either as implants or as inducers of bone regeneration, involves several processing stages including defatting and deproteination, yielding highly biocompatible systems with a suitable bioactivity and osteoconductivity. ${ }^{17,18}$ In the absence of an adequate supply of autogenous bone, there is an escalating demand for these types of biomaterials, in order to heal fractures and bone defects arising from chronic disease or trauma. Either synthetic materials or naturally sourced xenografts are preferable to allografts (bone grafts from the same species), since the latter bear the risks of disease transmission, rejection and infection. Moreover, xenografts from animal bone (not human) have been shown to display a high biocompatibility towards human live bone tissue, allowing them to act as reliable frames for new bone growth. This type of biocompatible material propagates after the native osteoblasts from the margin of the grafted defect, in two main stages: (i) codeposition of collagen on the new bone hydroxyapatite network; (ii) infiltration of new bone tissue into the implant. 
Consequently, an accurate assessment of the effect of the experimental defatting and deproteination processes on the characteristics of bone's inorganic matrix is paramount in order to attain suitable mechanical properties and features that are as similar as possible to those of the native tissue in order to decrease the likelihood of resorption or rejection..$^{18-20}$ To date, removal of organic material from mineralised tissues such as bone has been achieved by several methods including ethylenediamine extraction at high temperatures; ${ }^{21}$ long-term hydrazine treatment (after petroleum ether defatting) that triggers peptide bond rupture at mild temperatures (at 40-60 ${ }^{\circ} \mathrm{C}$ ); ${ }^{22} \mathrm{HCl}$ (or HF) demineralisation followed by dissolution of collagen in a weak acid solution; ${ }^{23,24}$ methyl acetate lipid extraction followed by deproteination by bleaching; ${ }^{18}$ alkaline hydrothermal hydrolysis; $;^{18,25}$ or the subcritical water process. ${ }^{25}$ Nevertheless, care must be taken regarding the effect of these experimental processes on the properties of bone's inorganic matrix, specifically on its structural and crystallinity profile. The use of ethylenediamine, for instance, has been shown to induce substantial molecular alterations in the apatite's network, ${ }^{26}$ while the impact of hydrazine extraction is still controversial. ${ }^{27-29}$ Moreover, neither of these reported methods leads to a complete elimination of bone's organic material.

Therefore, the aim of the present study is to develop a methodology that will enable a maximum deletion of bone's organic components with a minimum impact on its structure and crystallinity profile. A newly designed multi-enzymatic procedure is reported and compared with the widely used hydrazine protocol, through the application of high resolution vibrational spectroscopy. Fourier transform infrared (FTIR) and inelastic neutron scattering (INS) techniques have proven to be extremely valuable tools for studying bone samples under different conditions - e.g. intact, subject to burning events or to specific chemical handling, or even archaeological artefacts.,8,15,16,24,30-39

FTIR, mainly in attenuated total reflectance (ATR) mode, is a low-cost, non-destructive and rapid method for this type of analysis, that requires very small amounts of sample and yields very reliable data providing information on the chemical and structural characteristics of the bone, namely its organic components (protein and lipids), possible mineral contaminants (e.g. including fluorapatite (francolite), chloroapatite, cinnabar or gypsum) or pathology-induced changes.

INS, in turn, is an extremely powerful technique for probing hydrogenous materials and has been shown to be particularly useful for the analysis of bone, revealing even minor variations in composition..$^{\mathbf{8} 33,35,37,38}$ The INS intensity of each vibrational transition is normally expressed in terms of the so-called dynamic structure factor $S_{i}^{*}\left(Q, \nu_{\mathrm{k}}\right)$, which has the simplified expression, for a given atom

$$
S_{i}^{*}\left(Q, \nu_{\mathrm{k}}\right)=\frac{\left(Q^{2} u_{i}^{2}\right) \sigma}{3} \exp \left(-\frac{Q^{2} \alpha_{i}^{2}}{3}\right)
$$

where $Q\left(\AA^{-1}\right)$ is the momentum transferred to the sample, $\nu_{\mathrm{k}}$ is the energy of a vibrational mode, $\mathrm{u}_{i}(\AA)$ is the displacement vector of atom $i$ in mode $\mathrm{k}, \sigma$ is the neutron scattering cross section of the atom, and $\alpha_{i}(\AA)$ is related to a mass-weighted sum of the displacements of the atom in all vibrational modes. In contrast to the optical vibrational techniques, there are no selection rules for INS which yields all the fundamental modes and overtones of the analysed samples, as well as the combination bands.

The fact that any modification in the structure of bone is reflected in the corresponding vibrational pattern with high sensitivity - both regarding its inorganic framework (hydroxyapatite) and its organic constituents (lipids and proteins) - fully justifies the current use of complementary optical and neutronbased vibrational spectroscopies for appraising the effectiveness of defatting/deproteination processes, as well as their impact on bone's properties. Two different procedures were tested in samples of human femur and humerus: (i) hydrazine extraction, optimised from the formerly reported method;22 (ii) an enzymatic treatment, through the combined use of lipase $\mathrm{e}^{\mathbf{4 0}}$ and collagenase. FTIR-ATR and INS were applied, allowing access to all the vibrational modes of the samples, which was shown to be an extremely accurate methodology for monitoring the success of the different experimental procedures.

The results currently obtained are anticipated to be of relevance for future applications in forensic and archaeological contexts, as well as in the field of human health - regarding the development of novel biocompatible materials for drug delivery and orthopaedic xenografts.

\section{Experimental}

\subsection{Chemicals and materials}

Collagenase from Clostridium histolyticum (clostridiopeptidase type IA), hydrazine monohydrate $\left(\mathrm{NH}_{2} \mathrm{NH}_{2} \cdot \mathrm{H}_{2} \mathrm{O}, 98 \%\right)$, lipase from Aspergillus niger (lipase AP6), TES (2-[(2-hydroxy-1,1bis(hydroxymethyl)ethyl)amino]ethanesulfonic acid, >99\%), as well as solvents, inorganic salts and acids (of analytical grade) were purchased from Sigma-Aldrich (S.A. Sintra, Portugal). SRM 2910 b calcium hydroxyapatite $\left.\left[\mathrm{Ca}_{2}\left(\mathrm{PO}_{4}\right)_{6}(\mathrm{OH})_{2}\right)\right]$ was obtained from NIST (Gaithersburg, MA, USA). ${ }^{41}$

The bone samples were collected from unidentified human skeletons housed at the Laboratory of Forensic Anthropology of the University of Coimbra that have the same provenance of the identified skeletons from the $21^{\text {st }}$ century Collection of Identified Human Skeletons. ${ }^{42}$ These bones were already devoid of both soft tissue and marrow.

\subsection{Sample preparation}

Femoral and humeral diaphyses of two skeletons were analysed (Fig. 1). After cutting each bone section (using a Dremel minisaw electric tool), the samples were prepared by simple grinding of the intact bone followed by sieving (mesh size of 400 $\mu \mathrm{m})$, after mechanical removal of the outer layer through gentle sanding to avoid contaminants (providing ca. $10 \mathrm{~g}$ of each sample). According to previous infrared studies, ${ }^{32}$ no further cleaning is needed. For each type of bone, two adjacent bone slices were cut for analysis of either the intact sample or the defatted/deproteinated one (by each of the methods under study). 


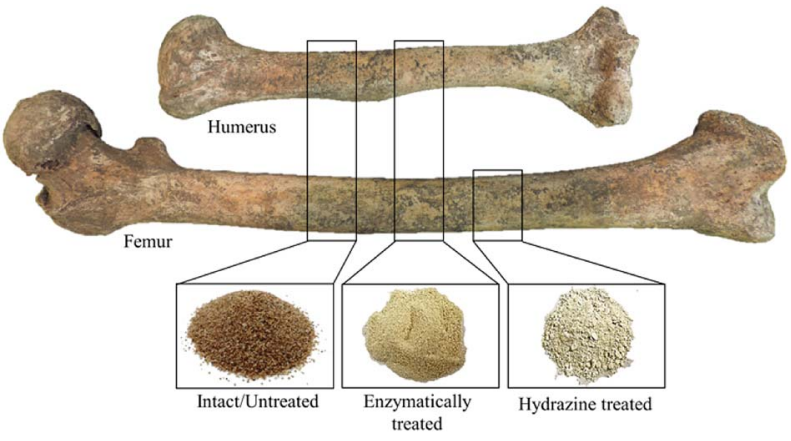

Fig. 1 Human femur and humerus cut sections presently analysed: intact, enzymatically and hydrazine treated (after grinding).

A highly crystalline sample of calcium hydroxyapatite from NIST (SRM 2910b, Ca/P = 1.67) was used as a reference (crystallinity index $=7.91$ as compared to poorly crystalline commercial HAp, $\mathrm{CI}=3.79$ ).

\subsection{Removal of the organic components}

Chemical defatting and deproteination of the human bone samples was carried out by two different experimental procedures: (i) hydrazine method, through an optimisation of the previously reported protocol;22,37 (ii) enzymatic treatment, following a procedure presently developed based on the combined use of a lipase and a collagenase.

Hydrazine method. Following removal of the lipid constituents by reflux with petroleum ether $(80: 20)$ for $10-12 \mathrm{~h}$, deproteination was performed by exposure to hydrazine $(95 \%)^{22}$ (ca. $10 \mathrm{~mL}$ per $\mathrm{g}$ of bone), with constant stirring $-1 \mathrm{~h}$ at room temperature and $24 \mathrm{~h}$ at $55^{\circ} \mathrm{C}$ (renewing hydrazine at $15 \mathrm{~h}$ ). The samples were washed with ethanol (80\%) (30 min), with absolute ethanol $(4 \times 30 \mathrm{~min})$ and with acetone $(95 \%)(3 \times 30 \mathrm{~min})$. Finally, they were dried in a rotary evaporator under vacuum (at $60{ }^{\circ} \mathrm{C}$ ) and then under a dry air flux for $c a .3 \mathrm{~h}$.

Enzymatic treatment. Lipids and proteins were enzymatically removed from the human bone samples using a lipase from Aspergillus niger ${ }^{40}$ followed by treatment with a collagenase from Clostridium histolyticum through a newly developed procedure, optimised for maximum organic component removal. For the lipase digestion, the bone powder was soaked in $200 \mathrm{~mL} \mathrm{Na}_{2} \mathrm{CO}_{3} / \mathrm{NaHCO}_{3}$ buffer solution $(\mathrm{pH}=9)$ containing $5 \%$ lipase $\left(w_{\text {enz }} / w_{\text {bone }}\right)$, for $5 \mathrm{~h}$ at $40{ }^{\circ} \mathrm{C}$ with constant stirring. For the collagenase enzymatic reaction the powdered samples were soaked in $200 \mathrm{~mL}$ TESCA buffer $(50 \mathrm{mM}$ TES, $0.36 \mathrm{mM}$ $\left.\mathrm{CaCl}_{2}, \mathrm{pH}=7.4\right)$ containing $0.01 \%$ collagenase $\left(w_{\text {enz }} / w_{\text {bone }}\right)$ and $4 \mathrm{~g} \mathrm{Ca}^{2+}$ per mole of enzyme, for $5 \mathrm{~h}$ at $37^{\circ} \mathrm{C}$ with constant stirring. The lipase treatment was performed prior to the collagenase hydrolysis in order to avoid interference from the lipid components in proteolytic activity ${ }^{43}$ Also, the control of the medium $\mathrm{pH}$ was essential in order to avoid enzymatic inactivation and ensure their maximum activity.

After the degradation reactions (of lipids and proteins), each enzyme was heat inactivated (at $70{ }^{\circ} \mathrm{C}$ for $15 \mathrm{~min}$ ) and the samples were washed with the respective buffer solution
$\left(\mathrm{Na}_{2} \mathrm{CO}_{3} / \mathrm{NaHCO}_{3}\right.$ or TESCA, for the lipase-treated or the collagenase-treated bone respectively). In order to remove noncollagenous proteins, the bones were then treated with $100 \mathrm{~mL}$ of sodium hypochlorite solution $(3.25 \%(\mathrm{w} / \mathrm{v}))$ for $10 \mathrm{~min}$, at room temperature, followed by washing with deionised water. Finally, the samples were dried in an oven at $110^{\circ} \mathrm{C}$ for $5 \mathrm{~h}$, and then under a dry air flux for $c a .24 \mathrm{~h}$.

Regarding the time of treatment, and the range of temperatures and $\mathrm{pH}$ values applied in the presently reported protocol, these were optimised for maximum efficiency and maintenance of the enzymes' activity upon probing different experimental conditions and defatting/deproteination outcomes.

\subsection{Fourier-transform infrared spectroscopy}

The FTIR-ATR were acquired using a Bruker Optics Vertex 70 FTIR spectrometer purged by $\mathrm{CO}_{2}$-free dry air. The measurements were taken for the bone powder samples on a Bruker Platinum ATR single reflection diamond accessory, using a Ge on $\mathrm{KBr}$ substrate beamsplitter and a liquid nitrogen cooled wide band mercury cadmium telluride (MCT) detector for the mid-IR interval $\left(400-4000 \mathrm{~cm}^{-1}\right)$.

Each spectrum was the sum of 128 scans, at $2 \mathrm{~cm}^{-1}$ resolution, and the 3-term Blackman-Harris apodization function was applied. Under these conditions, the wavenumber accuracy was better than $1 \mathrm{~cm}^{-1}$. The spectra were corrected for the frequency dependence of the penetration depth of the electric field in ATR (considering a mean reflection index of 1.25) using the Opus 7.2 spectroscopy software.

\subsection{Inelastic neutron scattering spectroscopy}

The INS experiments were performed at the ISIS Pulsed Neutron and Muon Source of the Rutherford Appleton Laboratory (United Kingdom), using the indirect geometry time-of-flight, high resolution broad range spectrometers MAPS $^{44,45}$ and TOSCA. ${ }^{46,47}$ The two spectrometers are complementary and have different strengths, these are explained more fully elsewhere. ${ }^{45}$ For the present work the key characteristics are that while both spectrometers have very high sensitivity, TOSCA is optimal in the low frequency region $\left(<1500 \mathrm{~cm}^{-1}\right)$ and MAPS for the high wavenumber range $\left(>2000 \mathrm{~cm}^{-1}\right)$. MAPS has the added advantage that it can access the entire spectrum in a single measurement (albeit with modest resolution, ${ }^{45}$ using the $5240 \mathrm{~cm}^{-1}$ incident energy), this allows simultaneous observation of the $\mathrm{OH}$ libration, its overtones and the $\mathrm{O}-\mathrm{H}$ stretch modes of bioapatite. In order to accurately observe each one of these signals, three incident energies were used, for the MAPS measurements - 968, 2024 and $5240 \mathrm{~cm}^{-1}$, respectively.

The samples (5-8 g) were wrapped in aluminium foil and fixed onto $4 \times 4 \mathrm{~cm}$ thin walled aluminium cans. To reduce the impact of the Debye-Waller factor on the observed spectral intensity, the samples were cooled to $c a .5 \mathrm{~K}$. Data were recorded in the energy range 0 to $6000 \mathrm{~cm}^{-1}$ (MAPS) and 0 to $4000 \mathrm{~cm}^{-1}$ (TOSCA), and converted to the conventional scattering law, $S(Q$, $\nu$ ) $v$ s. energy transfer (in $\mathrm{cm}^{-1}$ ) using the MANTID program (version 3.4.0). ${ }^{48}$ 


\section{Results and discussion}

The aim of the current study was to achieve an efficient protocol for the chemical defatting and deproteination of animal bone. A new enzymatic method was developed, based on the sequential treatment of human bone with a lipase and a collagenase, which was compared with the widely used hydrazine extraction process. Although lipase-defatting of porcine bone has already been performed and showed to be more efficient than the conventional $\mathrm{Na}_{2} \mathrm{CO}_{3} / \mathrm{NaHCO}_{3}$ processing, ${ }^{40}$ to the best of the authors' knowledge collagenase has never been applied for human bone deproteination, its use having been reported only for human dentin collagen fibrils. ${ }^{49}$

Complementary FTIR and INS techniques were applied, with a view to assess the effectiveness of each method and its potential impact on the inorganic framework of the bone tissue upon removal of its organic constituents (lipids and proteins). Hence, the enzyme- and hydrazine-exposed samples were compared with untreated bone (from the same bone type and region) and with highly crystalline calcium hydroxyapatite (taken as a reference for the inorganic framework).

Fig. 2 depicts the FTIR spectra of intact, hydrazine-extracted and enzymatically-treated samples of human femur. The presence of carbonate $\left(\mathrm{CO}_{3}{ }^{2-}\right)$ and phosphate $\left(\mathrm{PO}_{4}{ }^{3-}\right)$ functional groups within the bone's framework is evidenced by their characteristic bands, as well as the removal of most organic matter. Traces of protein were still detected for the enzymetreated bone (amide I signal at $1650 \mathrm{~cm}^{-1}$ ), while the feature observed at $c a .1630 \mathrm{~cm}^{-1}$ for the samples exposed to petroleum ether/hydrazine was assigned to $\mathrm{H}_{2} \mathrm{O}$ deformation modes (since its intensity decreased significantly upon sample drying). However, the infrared data alone does not allow us to retrieve definite conclusions regarding the exact extent of lipid or protein elimination from these bone samples.

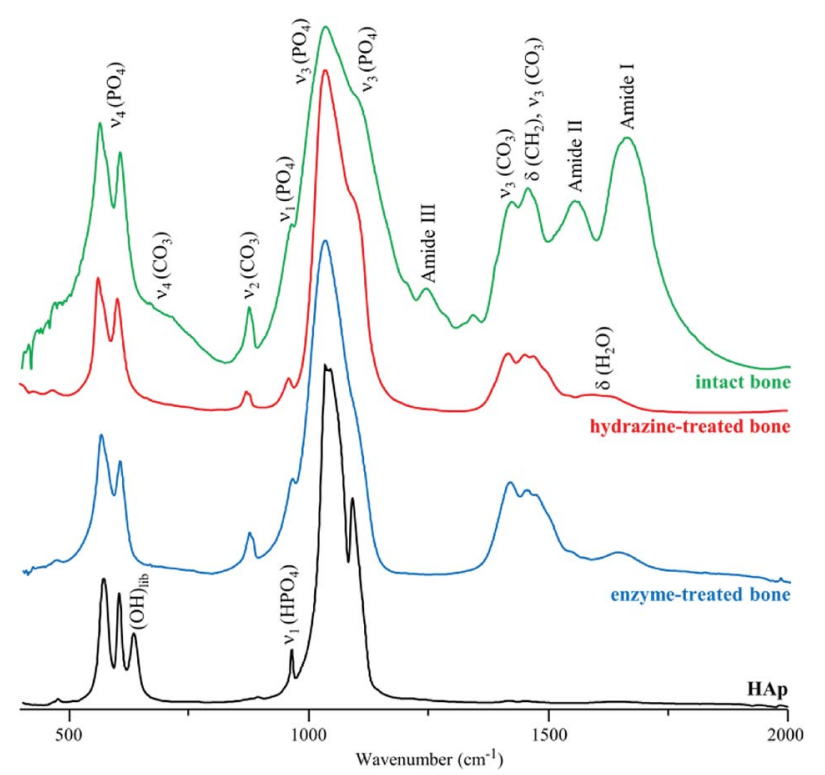

Fig. 2 FTIR-ATR spectra of human femur - intact, hydrazine- and enzyme-treated. The spectrum of reference calcium hydroxyapatite (HAp, SMR2910b) is also shown, for comparison.
Fig. 3 comprises the INS data measured for intact and processed bone with either hydrazine or lipase/collagenase at both TOSCA and MAPS. The use of both spectrometers enabled access to the samples' vibrational modes in the whole spectral window of interest, with high sensitivity and high resolution: the lower energy range (up to $1800 \mathrm{~cm}^{-1}$ ) in TOSCA, and the high frequency region (2000-4000 $\mathrm{cm}^{-1}$ ) in MAPS (Fig. 3). Comparison of this complementary data revealed that hydrazine extraction is a very efficient method for lipid elimination, but not as successful for protein extraction: the amide I and amide A bands are still detected (respectively at 1650 and $c a$. $3300 \mathrm{~cm}^{-1}$ in the MAPS spectra, in accordance with previous
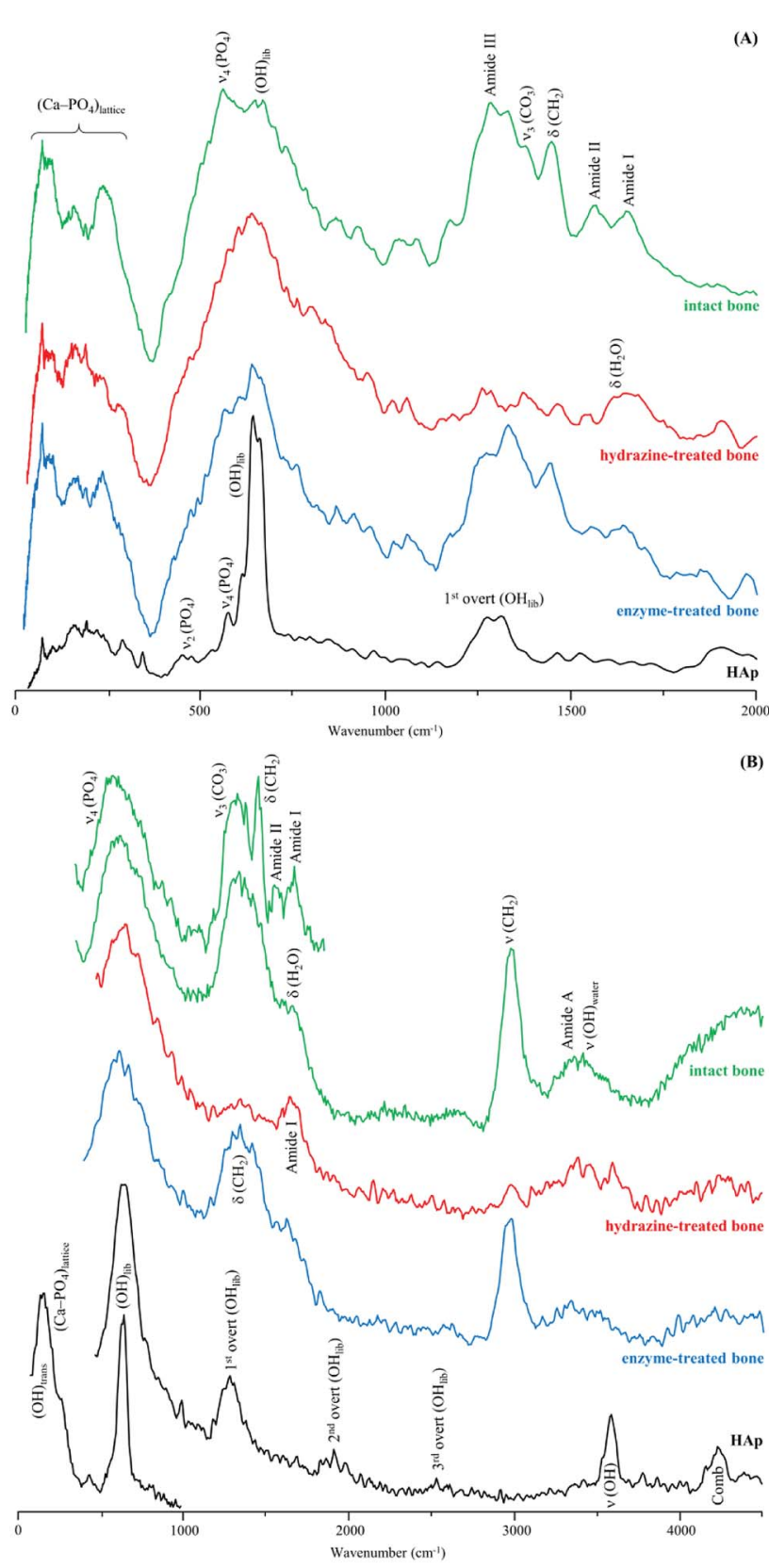

Fig. 3 INS spectra of human femur - intact, hydrazine- and enzymetreated - measured in two different spectrometers: (A) TOSCA and (B) MAPS (with 2024 and $5240 \mathrm{~cm}^{-1}$ incident energies). 
INS results $\left.{ }^{38}\right)$, while the $\delta\left(\mathrm{CH}_{2}\right)$ signal mainly due to the lipid constituents (centered at $1400 \mathrm{~cm}^{-1}$ ) is almost absent (Fig. 3(A) and (B)). Upon enzymatic treatment, in turn, virtually all protein was removed but there were still lipid components present, as shown by the strong band from $\mathrm{CH}_{2}$ deformations (observed in both TOSCA and MAPS spectra). The spectra of reference calcium hydroxyapatite (HAp, SMR2910b) is also shown, for comparison.

These results are in contrast with previous studies on hydrazine deproteination and lipase defatting of animal bone that reported a very high success of both protein ${ }^{22}$ and lipid ${ }^{40}$ elimination. This disagreement with our results can be explained by the fact that the previous work evaluated the protein and lipid content in the processed bone through techniques such as infrared spectroscopy or electron microscopy, which, as clearly revealed by the current study, are insufficient for accurately detecting the presence of remnant organic components in bone. Fig. 4 clearly evidences the importance of INS for this type of analysis: although the FTIR signature of enzymatically treated human femur shows hardly any trace of $\mathrm{CH}_{2}$ deformations (which are partially obscured by the carbonate stretching bands), the high sensitivity of INS to $\mathrm{H}^{-}$ associated vibrational modes unveils noticeable $\delta\left(\mathrm{CH}_{2}\right)$ and $\nu\left(\mathrm{CH}_{2}\right)$ signals reflecting the presence of lipids. In turn, the protein constituents are barely detected in this sample, the infrared band at $c a .3300 \mathrm{~cm}^{-1}$ being ascribed predominantly to the $\mathrm{OH}$ stretch from traces of contaminant ethanol (which is reported to occur in this frequency range at low temperatures ${ }^{50}$ ) and not to protein $\nu(\mathrm{NH})$ modes (amide A), since the protein content is very low as reflected by the weak infrared amide I signal.

The high efficiency of the enzymatic protocol regarding protein removal and its relatively poor efficacy concerning lipid elimination are a consequence of the high specificity of this type of treatment. While the applied collagenase is able to degrade the largely predominant protein component of bone (collagen

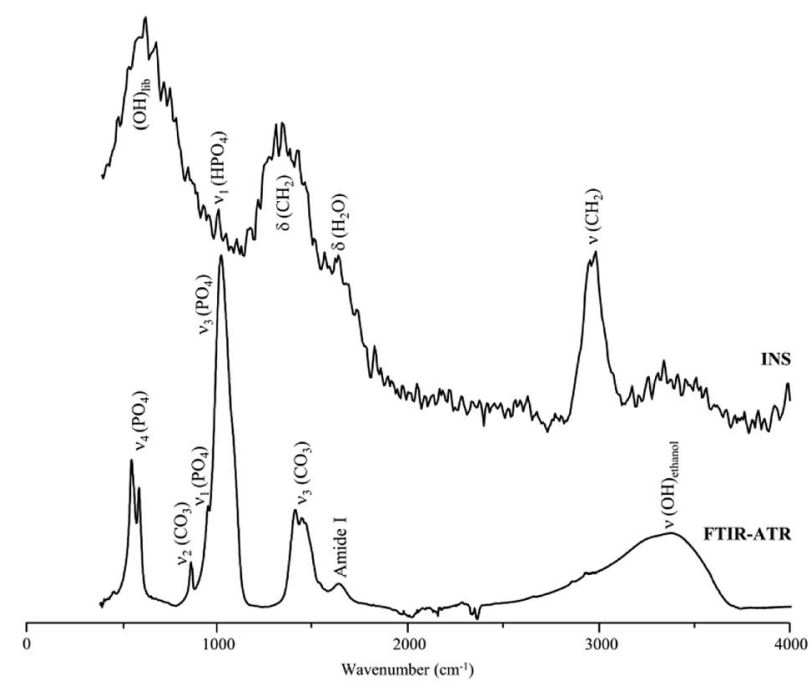

Fig. 4 FTIR-ATR and INS spectra of enzyme-treated human femur. The INS data was measured in the MAPS spectrometer (with a $5240 \mathrm{~cm}^{-1}$ incident energy). type I), the large variety of lipids present cannot be digested by the sole Aspergillus niger lipase currently used, since it only recognises mono-, di- and triacylglycerols as substrates. Hence, a considerable amount of lipids were still left in the bone samples after enzymatic treatment, along with residual traces of non-collagenous proteins (not completely removed by sodium hypochlorite washing). This prompts the need for further optimisation of the experimental protocol, by adding a mixture of different types of lipases aimed at the hydrolysis of the distinct lipids that are contained in the mineralized bone tissue (apart from the marrow): from triglycerides, phospholipids, cholesterol and prostaglandins to essential fatty acids directly incorporated from the diet.

No significant variations were found regarding the outcome of either hydrazine-exposed or enzymatic-treated samples according to the type of bone currently analysed, identical results having been observed for both femur and humerus.

The low frequency region of the INS spectra, acquired with TOSCA for intact and treated bones, as well as for reference HAp (Fig. 5), allow us to assess the potential effect of the defatting and deproteination procedures on bone's inorganic matrix. The features in the 190 to $310 \mathrm{~cm}^{-1}$ interval, mainly ascribed to the $\left(\mathrm{Ca}-\mathrm{PO}_{4}\right)$ network, appear to be more affected by hydrazine extraction than by the enzymatic treatment. These results contradict the previously reported maintenance of the overall $\mathrm{Ca} / \mathrm{P}$ ratio in hydrazine-processed bone, despite the small decrease in phosphate and carbonate content measured for these samples. ${ }^{22}$ Moreover, previous TEM (Transmission Electron Microscopy) observation of these samples evidenced no morphology changes. ${ }^{22}$

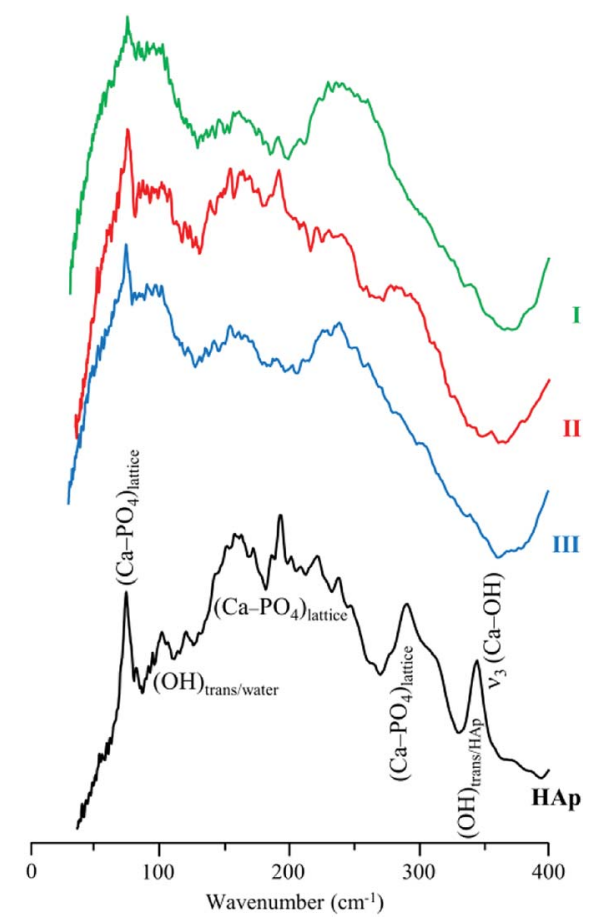

Fig. 5 Low energy INS spectra of human femur, measured with the TOSCA spectrometer: intact (I), hydrazine-treated (II) and enzymetreated (III). The spectrum of reference calcium hydroxyapatite (HAp, SMR2910b) is also shown, for comparison. 
The hydroxyapatite's $\mathrm{OH}_{\mathrm{lib}}$ characteristic peak, clearly detected in both the TOSCA and MAPS INS profiles (Fig. 3), is a good spectral probe of crystallinity of the bone's inorganic matrix. Despite its expected broadening with decreasing sample crystallinity (i.e. from HAp to defatted/deproteinated and intact bone), no significant shifts were observed in the transition energy from that of the reference HAp $\left(630 \mathrm{~cm}^{-1}\right)$ to bone samples subject to either hydrazine or enzymatic treatment (637 and $636 \mathrm{~cm}^{-1}$, respectively). The splitting of the $\nu_{4}\left(\mathrm{PO}_{4}\right)$ infrared signals (at 565 and $603 \mathrm{~cm}^{-1}$ ) is also a reliable measure of the crystal microstructure of hydroxyapatite, ${ }^{\mathbf{4 , 8 , 1 6 , 5 1 , 5 2}}$ and is commonly quantified by the crystallinity index (CI) calculated as the sum of the heights of the two $\nu_{4}\left(\mathrm{PO}_{4}\right)$ absorption bands divided by the height of the minimum between them. ${ }^{8}$ The CI values presently obtained for HAp, intact bone, hydrazine- and enzyme-exposed samples, respectively 7.56, 2.89, 3.49 and 3.04 clearly reflect a decrease of the degree of crystallinity from the reference hydroxyapatite to the processed bone samples, the intact bone being the most amorphous material, as anticipated. When comparing the CI indexes for the hydrazine- and enzymatically treated samples the former reveals a slightly higher crystallinity, which is in agreement with the results formerly reported by Karampas and collaborators. ${ }^{28}$ Hence, the hydrazine method has a higher impact on bone's crystallinity as compared to the enzymatic process.

Contrary to Termine and coworkers' results for a single hydrazine treatment cycle, ${ }^{22}$ Karampas found that hydrazine deproteination (upon several protocol cycles) induced a significant increase of HAp crystal size and crystallinity, that could not be attributed to the elimination of collagen. These crystallinity changes were suggested to be triggered by a hydrazine-induced partial removal of $\mathrm{CO}_{3}{ }^{2-}$ and $\mathrm{HPO}_{4}{ }^{2-}$ ions from bone's inorganic network, which are then substituted by $\mathrm{OH}^{-}$and $\mathrm{PO}_{4}{ }^{3-}$, giving rise to a new bioapatite framework with a strong resemblance to stoichiometric hydroxyapatite.

\section{Conclusions}

In the last decades, several techniques have been proposed to separate bone's organic materials from its inorganic (hydroxyapatite) matrix. However, preservation of the original characteristics of bone (both mechanical and chemical) has constituted a major challenge: all reported methods up to this date having been found to elicit some variations in the bone's structure and crystallinity features.

Coupled FTIR and INS techniques were presently applied to evaluate the success of two experimental protocols for human bone defatting and deproteination - hydrazine extraction and sequential enzymatic treatment with a lipase and a collagenase. INS was shown to be of paramount importance for this type of analysis, in view of its particular sensitivity to vibrational modes involving hydrogen, which is very abundant in bone's inorganic and organic constituents.

Overall, the newly proposed enzymatic process to bone tissue defatting and deproteination was found to be quite promising, leading to a very efficient protein elimination and a partial separation of the lipids, while obtaining a bone mineral with properties as close as possible to the native state. Further optimisation is still needed in order to achieve a more extensive removal of the lipidic fraction, by using a mixture of lipases (instead of just one) which is required due to the high diversity of lipids present in bone.

The results delivered by this study are anticipated to have an impact on several areas, from forensic, bioanthropological and archaeological sciences to medicine. The development of biocompatible and low cost matrices for use as osteoconductive scaffolds for bone repair or replacement is a particularly significant application of animal bone (devoid of organic components), and meets a growing need for this type of biomaterials.

\section{Conflicts of interest}

There are no conflicts to declare.

\section{Acknowledgements}

The authors thank financial support from the Portuguese Foundation for Science and Technology - UID/MULTI/00070/ 2013, PEst-OE/SADG/UI0283/2013, PTDC/IVC-ANT/1201/2014, POCI-01-0145-FEDER-016766 and SFRH/BPD/84268/2012. The STFC Rutherford Appleton Laboratory is thanked for access to neutron beam facilities.

\section{References}

1 B. Clarke, Normal Bone Anatomy and Physiology, Clin. J. Am. Soc. Nephrol., 2008, 3, S131-S139, DOI: 10.2215/ CJN.04151206.

2 X. Y. Wang, Y. Zuo, D. Huang, X. D. Hou and Y. B. Li, Comparative study on inorganic composition and crystallographic properties of cortical and cancellous bone, Biomed. Environ. Sci., 2010, 23, 473-480, DOI: 10.1016/ S0895-3988(11)60010-X.

3 R. Vassalo, E. Cunha, L. A. E. Batista de Carvalho and D. Gonçalves, Rather yield than break: assessing the influence of human bone collagen content on heat-induced warping through vibrational spectroscopy, Int. J Legal Med., 2016, 130, 1647-1656, DOI: 10.1007/s00414-016-1400-x.

4 S. Weiner and O. Bar-Yosef, States of preservation of bones from prehistoric sites in the Near East: a survey, J. Archaeol. Sci., 1990, 17, 187-196, DOI: 10.1016/03054403(90)90058-D.

5 R. Shahack-Gross, O. Bar-Yosef and S. Weiner, BlackColoured Bones in Hayonim Cave, Israel: Differentiating Between Burning and Oxide Staining, J. Archaeol. Sci., 1997, 24, 439-446, DOI: 10.1006/jasc.1996.0128.

6 S. T. D. Ellingham, T. J. U. Thompson, M. Islam and G. Taylor, Estimating temperature exposure of burnt bone a methodological review, Sci. Justice, 2015, 55, 181-188, DOI: 10.1016/j.scijus.2014.12.002.

7 S. T. D. Ellingham, T. J. U. Thompson and M. Islam, The Effect of Soft Tissue on Temperature Estimation from Burnt Bone Using Fourier Transform Infrared 
Spectroscopy, J. Forensic Sci., 2016, 61, 153-159, DOI: 10.1111/1556-4029.12855.

8 P. Mamede, D. Gonçalves, M. P. M. Marques and L. A. E. Batista de Carvalho, Burned bones tell their own stories: a review of methodological approaches to assess heat-induced diagenesis, Appl. Spectrosc. Rev., 2018, 53, 603-635.

9 M. C. Stiner, S. L. Kuhn, T. A. Surovell, P. Goldberg, L. Meignen, S. Weiner and O. Bar-Yosef, Bone Preservation in Hayonim Cave (Israel): a Macroscopic and Mineralogical Study, J. Archaeol. Sci., 2001, 28, 643-659, DOI: 10.1006/ jasc.2000.0634.

10 T. A. Surovell and M. C. Stiner, Standardizing Infra-red Measures of Bone Mineral Crystallinity: An Experimental Approach, J. Archaeol. Sci., 2001, 28, 633-642, DOI: 10.1006/jasc.2000.0633.

11 M. Arroyo, M. D. L. Ruiz, G. V. Bernabeu, R. S. Román, M. R. G. Morales and L. G. Straus, Archaeological implications of human-derived manganese coatings: a study of blackened bones in El Mirón Cave, J. Archaeol. Sci., 2008, 35, 801-813.

12 G. Piga, A. Malgosa, T. J. U. Thompson and S. Enzo, A new calibration of the XRD technique for the study of archaeological burned human remains, J. Archaeol. Sci., 2008, 35, 2171-2178, DOI: 10.1016/j.jas.2008.02.003.

13 G. Piga, T. J. U. Thompson, A. Malgosa and S. Enzo, The Potential of X-Ray Diffraction in the Analysis of Burned Remains from Forensic Contexts, J. Forensic Sci., 2009, 54, 534-539, DOI: 10.1111/j.1556-4029.2009.01037.x.

14 M. Lebon, I. Reiche, J. J. Bahain, C. Chadefaux, A. M. Moigne, F. Fröhlich, F. Sémah, H. P. Schwarcz and C. Falguères, New parameters for the characterization of diagenetic alterations and heat-induced changes of fossil bone mineral using Fourier transform infrared spectrometry, J. Archaeol. Sci., 2010, 37, 2265-2276, DOI: 10.1016/j.jas.2010.03.024.

15 M. M. Beasley, E. J. Bartelink, L. Taylor and R. M. Miller, Comparison of transmission FTIR, ATR, and DRIFT spectra: Implications for assessment of bone bioapatite diagenesis, J. Archaeol. Sci., 2014, 46, 16-22, DOI: 10.1016/ j.jas.2014.03.008.

16 C. Snoeck, J. A. Lee-Thorp and R. J. Schulting, From bone to ash: Compositional and structural changes in burned modern and archaeological bone, Palaeogeogr., Palaeoclimatol., Palaeoecol., 2014, 416, 55-68, DOI: 10.1016/ j.palaeo.2014.08.002.

17 G. S. Johnson, M. R. Mucalo, M. A. Lorier, U. Gieland and H. Mucha, The processing and characterization of animalderived bone to yield materials with biomedical applications. Part II: milled bone powders, reprecipitated hydroxyapatite and the potential uses of these materials, J. Mater. Sci.: Mater. Med., 2000, 11, 725-741, DOI: 10.1023/ A:1008979929632.

18 G. S. Johnson, M. R. Mucalo and M. A. Lorier, The processing and characterization of animal-derived bone to yield materials with biomedical applications. Part 1: Modifiable porous implants from bovine condyle cancellous bone and characterization of bone materials as a function of processing, J. Mater. Sci.: Mater. Med., 2000, 11, 427-441, DOI: $10.1023 / \mathrm{A}: 1008987908917$.

19 I. Anderson, M. Mucalo, G. Johnson and M. Lorier, The processing and characterization of animal- derived bone to yield materials with biomedical applications. Part III: material and mechanical properties of fresh and processed bovine cancellous bone, J. Mater. Sci.: Mater. Med., 2000, 11, 743-749.

20 J. T. B. Ratnayake, M. L. Gould, A. Shavandi, M. Mucalo and G. J. Dias, Development and characterization of a xenograft material from New Zealand sourced bovine cancellous bone, J. Biomed. Mater. Res., Part B, 2016, 105, 1054-1062, DOI: $10.1002 / \mathrm{jbm}$. b.33644.

$21 \mathrm{~J}$. Williams and J. Irvine, Preparation of the inorganic matrix of bone, Sci. 80, 1954, 119, 771-772.

22 J. D. Termine, E. D. Eanes, D. J. Greenfield, M. U. Nylen and R. A. Harper, Hydrazine-deproteinated bone mineral, Calcif. Tissue Res., 1973, 12, 73-90, DOI: 10.1007/BF02013723.

$23 \mathrm{R}$. Longin, New method of collagen extraction for radiocarbon dating, Nature, 1971, 230, 241-242, DOI: 10.1038/230241a0.

24 F. Maspero, S. Sala, M. E. Fedi, M. Martini and A. Papagni, A new procedure for extraction of collagen from modern and archaeological bones for 14C dating, Anal. Bioanal. Chem., 2011, 401, 2019-2023, DOI: 10.1007/s00216-011-5252-4.

25 N. A. M. Barakat, M. S. Khil, A. M. Omran, F. A. Sheikh and H. Y. Kim, Extraction of pure natural hydroxyapatite from the bovine bones bio waste by three different methods, J. Mater. Process. Technol., 2009, 209, 3408-3415, DOI: 10.1016/j.jmatprotec.2008.07.040.

26 J. D. Termine and A. S. Posner, Amorphous/crystalline interrelationships in bone mineral, Calcif. Tissue Res., 1967, 1, 8-23, DOI: 10.1007/BF02008070.

27 D. Carter, A. Scully, D. Heaton, M. P. Young and J. Aaron, Effect of deproteination on bone mineral morphology: implications for biomaterials and aging, Bone, 2002, 31, 389-395, DOI: 10.1016/S8756-3282(02)00840-2.

28 I. A. Karampas, M. G. Orkoula and C. G. Kontoyannis, Effect of hydrazine based deproteination protocol on bone mineral crystal structure, J. Mater. Sci.: Mater. Med., 2012, 23, 11391148, DOI: 10.1007/s10856-012-4593-7.

29 S. Bertazzo and C. A. Bertran, Effect of hydrazine deproteination on bone mineral phase: a critical view, J. Inorg. Biochem., 2008, 102, 137-145, DOI: 10.1016/ j.jinorgbio.2007.07.031.

30 F. Khan, M. Awais, A. S. Khan, S. Tabassum, A. A. Chaudhry and I. U. Rehman, Raman Spectroscopy of Natural Bone and Synthetic Apatites, Appl. Spectrosc. Rev., 2013, 48, 329-355, DOI: $10.1080 / 05704928.2012 .721107$.

31 H. I. Hollund, F. Ariese, R. Fernandes, M. M. E. Jans and H. Kars, Testing an alternative high-throughput tool for investigating bone diagenesis: FTIR in attenuated total reflection (ATR) mode, Archaeometry, 2013, 55, 507-532, DOI: $10.1111 / \mathrm{j} .1475-4754.2012 .00695 . x$.

32 T. J. U. Thompson, M. Islam and M. Bonniere, A new statistical approach for determining the crystallinity of 
heat-altered bone mineral from FTIR spectra, J. Archaeol. Sci., 2013, 40, 416-422, DOI: 10.1016/j.jas.2012.07.008.

33 M. P. M. Marques, D. Gonçalves, A. I. C. Amarante, C. I. Makhoul, S. F. Parker and L. A. E. Batista de Carvalho, Osteometrics in burned human skeletal remains by neutron and optical vibrational spectroscopy, RSC Adv., 2016, 6, 68638-68641, DOI: 10.1039/C6RA13564A.

34 G. Piga, M. D. Baró, I. G. Escobal, D. Gonçalves, C. Makhoul, A. Amarante, A. Malgosa, S. Enzo and S. Garroni, A structural approach in the study of bones: fossil and burnt bones at nanosize scale, Appl. Phys. A, 2016, 122, 1031, DOI: 10.1007/s00339-016-0562-1.

35 C.-K. Loong, C. Rey, L. T. Kuhn, C. Combes, Y. Wu, S.-H. Chen and M. J. Glimcher, Evidence of hydroxyl-ion deficiency in bone apatites: an inelastic neutron-scattering study, Bone, 2000, 26, 599-602, DOI: 10.1016/S87563282(00)00273-8.

36 A. Carden and M. D. Morris, Application of vibrational spectroscopy to the study of mineralized tissues (review), J. Biomed. Opt., 2000, 5, 259, DOI: 10.1117/1.429994.

37 M. G. Taylor, S. F. Parker, K. Simkiss and P. C. H. Mitchell, Bone mineral: evidence for hydroxy groups by inelastic neutron scattering, Phys. Chem. Chem. Phys., 2001, 3, 15141517, DOI: 10.1039/b005666i.

38 M. G. Taylor, S. F. Parker and P. C. H. Mitchell, A study by high energy transfer inelastic neutron scattering spectroscopy of the mineral fraction of ox femur bone, J. Mol. Struct., 2003, 651-653, 123-126, DOI: 10.1016/S00222860(03)00102-9.

39 H. G. M. Edwards, F. Sadooni, P. Vitek and J. Jehlicka, Raman spectroscopy of the Dukhan sabkha: identification of geological and biogeological molecules in an extreme environment, Philos. Trans. R. Soc., A, 2010, 368, 30993107, DOI: 10.1098/rsta.2010.0101.

40 N. Zhang, M. Zhou, Y. Zhang, X. Wang, S. Ma, L. Dong, T. Yang, L. Ma and B. Li, Porcine bone grafts defatted by lipase: efficacy of defatting and assessment of cytocompatibility, Cell Tissue Banking, 2014, 15, 357-367, DOI: $10.1007 / \mathrm{s} 10561-013-9391-z$.

41 National Institute of Standards and Technology (NIST), (n.d.), http://1.usa.gov/1WcMIO2, (accessed March 14, 2018).

42 M. T. Ferreira, R. Vicente, D. Navega, D. Gonçalves, F. Curate and E. Cunha, A new forensic collection housed at the University of Coimbra, Portugal, the 21st century identified skeletal collection, Forensic Sci. Int., 2014, 245, 202.e1202.e5, DOI: 10.1016/j.forsciint.2014.09.021.

43 L. Kalvodova, N. Kahya, P. Schwille, R. Ehehalt, P. Verkade, D. Drechsel and K. Simons, Lipids as Modulators of Proteolytic Activity of BACE, J. Biol. Chem., 2005, 280, 36815-36823, DOI: 10.1074/jbc.M504484200.

44 ISIS Facility, INS - MAPS, (n.d.), https://www.isis.stfc.ac.uk/ Pages/maps.aspx, (accessed March 23, 2018).

45 S. F. Parker, D. Lennon and P. W. Albers, Vibrational spectroscopy with neutrons: A review of new directions, Appl. Spectrosc., 2011, 65, 1325-1341, DOI: 10.1366/11-06456. 46 ISIS Facility, INS - TOSCA, (n.d.), https://www.isis.stfc.ac.uk/ Pages/tosca.aspx, (accessed March 23, 2018).

47 S. F. Parker, F. Fernandez-Alonso, A. J. Ramirez-Cuesta, J. Tomkinson, S. Rudic, R. S. Pinna, G. Gorini and J. Fernández Castañon, Recent and future developments on TOSCA at ISIS, J. Phys. Conference, 2014, 554, 012003.

48 O. Arnold, J. C. Bilheux, J. M. Borreguero, A. Buts, S. I. Campbell, L. Chapon, M. Doucet, N. Draper, R. Ferraz Leal, M. A. Gigg, V. E. Lynch, A. Markvardsen, D. J. Mikkelson, R. L. Mikkelson, R. Miller, K. Palmen, P. Parker, G. Passos, T. G. Perring, P. F. Peterson, S. Ren, M. A. Reuter, A. T. Savici, J. W. Taylor, R. J. Taylor, R. Tolchenov, W. Zhou and J. Zikovsky, Mantid-Data analysis and visualization package for neutron scattering and $\mu$ SR experiments, Nucl. Instruments Methods Phys. Res. Sect. A Accel. Spectrometers, Detect. Assoc. Equip., 2014, 764, 156-166, DOI: 10.1016/j.nima.2014.07.029.

49 X. Zheng, H. Pan, Z. Wang and H. Chen, Real-time enzymatic degradation of human dentin collagen fibrils exposed to exogenous collagenase: an AFM study in situ, J. Microsc., 2011, 241, 162-170, DOI: 10.1111/j.1365-2818.2010.03412.x.

50 P. Golub, I. Doroshenko, V. Pogorelov, V. Sablinskas, V. Balevicius and J. Ceponkus, Temperature Evolution of Cluster Structures in Ethanol, Dataset Papers in Physics, 2013, 2013, 1-4, DOI: 10.1155/2013/473294.

51 T. J. U. Thompson, M. Gauthier and M. Islam, The application of a new method of Fourier Transform Infrared Spectroscopy to the analysis of burned bone, J. Archaeol. Sci., 2009, 36, 910-914, DOI: 10.1016/j.jas.2008.11.013.

52 D. Gonçalves, A. R. Vassalo, A. P. Mamede, C. Makhoul, G. Piga, E. Cunha, M. P. M. Marques and L. A. E. Batista de Carvalho, Crystal clear: vibrational spectroscopy reveals intrabone, intraskeleton, and interskeleton variation in human bones, Am. J. Phys. Anthropol., 2018, 166, 296-312. 